Research Article

\title{
Comparison of DMA-80 and ICP-MS Combined with Closed-Vessel Microwave Digestion for the Determination of Mercury in Coal
}

\author{
Siyu Zhang $\mathbb{D D}^{1,2}$ and Mingxuan Zhou ${ }^{1,2}$ \\ ${ }^{1}$ State Key Laboratory of Coal Resources and Safe Mining, China University of Mining and Technology, Beijing 100083, China \\ ${ }^{2}$ College of Geoscience and Survey Engineering, China University of Mining and Technology (Beijing), Beijing 100083, China \\ Correspondence should be addressed to Siyu Zhang; 15801193096@163.com
}

Received 14 September 2020; Accepted 5 December 2020; Published 18 December 2020

Academic Editor: Radosław Kowalski

Copyright (c) 2020 Siyu Zhang and Mingxuan Zhou. This is an open access article distributed under the Creative Commons Attribution License, which permits unrestricted use, distribution, and reproduction in any medium, provided the original work is properly cited.

As one of the most widely used techniques for concentration determination of trace elements in coal, inductively coupled plasma mass spectrometry (ICP-MS) has also been used in several studies for the determination of mercury concentration in coal. ICPMS after closed-vessel microwave digestion and a Milestone DMA-80 are employed in this study to determine the mercury concentration in coal. Three NIST standard references of coal samples were selected as references to verify the accuracy of the test results. The Au rinse solution $\left(200 \mu \mathrm{g} / \mathrm{L}, 5 \% \mathrm{HNO}_{3}\right)$ can diminish mercury memory effects to a blank level within 80 seconds. The results showed that ICP-MS can accurately determine the mercury content in mercury standard solutions, but the mercury concentration in most NIST samples after microwave digestion is lower than the detection level of the ICP-MS. The inaccuracy may be due to volatilization of mercury during solid sample digestion process. By contrast, the determined concentrations in NIST samples by the Milestone DMA- 80 are very close to the verified values. Therefore, ICP-MS is not recommended to analyze mercury in coal after digestion even in a closed-vessel digestion system, but the mercury direct analyzer (without digestion) is recommended to analyze mercury in coal.

\section{Introduction}

Mercury is a toxic element that can cause serious environmental and human health problems when it is released into the atmosphere. Approximately, 30\% of mercury released into the atmosphere each year is from anthropogenic sources, such as mining, burning of fossil fuels, and intentional use of Mercury [1]. Artisanal, small-scale goldmining activity and coal combustion in power plants are the largest sectors of the anthropogenic emission [1-3]. Mercury occurs in rocks and soils in the earth's crust $[1,4]$, accounting for about $10 \%$ of mercury emissions from natural geological sources. Previously released mercury accumulated in surface soils and oceans, most of which was rereleased due to human activities, and this rereleased mercury accounts for the remaining 60\% [1]. Mercury can remain in the air for a long time and be transported for long distances $[3,4]$. Humans and wildlife can be exposed to this mercury, and, if it reaches a certain level, it will cause harm to their health. Consumption of aquatic products containing high levels of methylmercury is another common way of people's route of exposure to mercury [4-6]. High levels of methylmercury in the human body can harm the nervous system and other organ systems [7]. Therefore, the emission of mercury must be taken seriously.

Due to the presence of mercury in coal and the volatility of mercury, coal combustion can cause mercury to be released into the atmosphere. The average concentration of mercury in the world hard coal is $0.1 \mathrm{ppm}$ [8], the average concentration of mercury in the United States coal is $0.17 \mathrm{ppm}$ [9], and the average concentration of mercury in Chinese coals is $0.163 \mathrm{ppm}$ [10]. Many researchers have also 
investigated the origin of mercury in coal. Finkelman (1980) found that $\mathrm{Hg}$ in coal is associated with pyrite, probably of secondary origin [11]. Zhou proposed that the origin types of $\mathrm{Hg}$ in coal are mainly terrigenous sedimentary type and epigenetic hydrothermal type [12]. Yudovich and Ketris also suggested that the origin of thermal epigenetic $\mathrm{Hg}$ in coal mainly occurs in epigenetic Hg-bearing sulfides in coals, syngenetic pyrite, and hydrothermal solutions [13]. Although the concentration of mercury in coal is modest (generally, less than $0.17 \mathrm{ppm}$ compared to $0.5 \mathrm{ppm}$ in the earth's crust), the tremendous volumes of coal consumption each year (almost $3.73 \mathrm{Gt}$ oil equivalent worldwide with about half from China [14]) result in substantial mercury emissions. In addition, millions of tons of in-ground and near surface coal and coal waste burn each year, thus releasing mercury into the atmosphere [15]. In 2017, thermal power accounted for about 62 percent of China's total power generation [16]. Mercury emissions from China's coal-fired power plants are serious and alarming. Attention should be paid to the concentration and occurrence of mercury in coal, which is closely related to mercury emissions from coal. Accurate quantification of mercury in coal is of great importance in assessing the importance of mercury emissions from coal combustion.

Several analytical methods have been used for determination of mercury in solid samples, including neutron activation analysis (NAA) [17-19], cold-vapor atomic absorption spectrometry (CV-AAS) [20-23], cold vapor atomic fluorescence spectroscopy (CVAFS) [24-29], atomic fluorescence spectroscopy (AFS) $[22,30,31]$, and direct mercury analyzer based on concepts of cold vapor atomic absorption spectrometry [32-35].Among these techniques, CV-AAS is the most reliable approach and has been widely used for $\mathrm{Hg}$ determination in coal $[28,36,37]$. Yudovich and Ketris have pointed out [13] "the best available method for $\mathrm{Hg}$ analysis of solids (coal, ash, and sulfate wastes) is EPA7473 [38] using an instrument such as the DMA-80 (a direct mercury analyzer, Milestone)."

ICP-MS currently is the most common analytical method for concentration determination of trace elements due to its sensitivity and efficiency [39-44]. Some researchers used ICP-MS or ICP-MS-related technologies to determine $\mathrm{Hg}$ concentration in coal and coal fly ash, utilizing techniques such as slurry sampling electrothermal vaporization ICP-MS [45], isotope dilution cold-vapor generation ICP-MS [5], ICP-MS with microwave digestion [46], and ICP-MS after digestion using microwave-induced combustion [47]. However, most of these analytical methods are too complex to be applied to routine testing [41]. The most serious problem when using ICP-MS for mercury analysis that should be addressed is the mercury memory effect $[40,41,44,48]$, because the detection of mercury in solid samples by ICP-MS requires the extraction of mercury from solid samples into aqueous solutions, mercury can adhere to the walls of the sample-introduction system even at very low concentration [39], resulting in a strong memory effort, and therefore, the accuracy of the test results will not be guaranteed.
A number of methods have been developed to eliminate the mercury memory effect during the concentration determination of $\mathrm{Hg}$ using ICP-MS, such as gold addition $[49,50]$, Triton X-100/ammonia/ethylenediaminetetraacetic acid (EDTA) addition $[29,51,52]$, hydrobromic acid addition [53, 54], 2-mercaptoethanol (ME) addition in carrier solution [48], and mixing mercury with $\left(\mathrm{NH}_{4}\right)_{2} \mathrm{H}_{2}$ EDTA and the presence of ammonia addition [52].

In this paper, we describe a rinse solution optimized to minimize the mercury memory effect in the shortest possible time, and subsequently, ICP-MS analysis, after closed-vessel microwave digestion, is used to check if this technique can be used to determine mercury concentrations in coal.

\section{Methods and Materials}

\subsection{Apparatus}

2.1.1. ICP-MS and Digestion System. A Thermo Fisher inductively coupled plasma mass spectrometry (X Series II) was used to determine the mercury concentrations in coal samples. The coal samples were digested by using an UltraClave microwave high-pressure reactor (Milestone) prior to ICP-MS analysis. The UltraClave microwave system digests samples by high temperature and high pressure, which can greatly reduce the time required for sample digestion and avoid cross-contamination between samples $[55,56]$.

2.1.2. DMA-80 Mercury Analyzer. In contrast to the steps of analyzing samples with ICP-MS, the DMA-80 mercury analyzer measures mercury content in the coal sample by direct combustion. The sample was weighed into a metal boat, and the sample contained in the metal tube is dried and thermally decomposed in the oxygen-rich furnace. The generated gases (including mercury and other combustion products, e.g., nitrogen, halogens, and sulfur oxides) are carried to the catalytic furnace and purified by the adsorbent, where various species of $\mathrm{Hg}$ are converted into elemental $\mathrm{Hg}$. The mercury is selectively trapped, and the other combustion by-products are flushed off by gold amalgamation. The amalgamation furnace is heated, and mercury is rapidly released. Mercury is carried into the optical cell by oxygen flow for atomic absorption measurement at a wavelength of $253.65 \mathrm{~nm}$. The mercury content in the sample was determined according to Beer's law working curve method. The detection limit of mercury is $0.005 \mathrm{ng}$, the relative standard deviation (RSD) from eleven runs on a mercury standard reference is $1.5 \%$, and the linearity of the calibration is in the range $0-1000 \mathrm{ng}$. It will take about five minutes to test one sample by the DMA-80 mercury analyzer.

\subsection{Reagents, Gases, Standard Solutions, and Investigated Samples}

2.2.1. Reagents. MOS (metal-oxide-semiconductor)-reagent $\mathrm{HF}(40 \%, \mathrm{v} / \mathrm{v})$, the guaranteed reagent $\mathrm{HNO}_{3}(65 \%$, v/v), auric standard solution $\left(200 \mu \mathrm{g} / \mathrm{L}, 5 \% \mathrm{HNO}_{3}\right)$, MOS-reagent $\mathrm{HCl}$, 
the guaranteed reagent $\mathrm{H}_{2} \mathrm{SO}_{4}(98 \%)$, analytical reagent $\mathrm{H}_{2} \mathrm{O}_{2}$ $(30 \%, v / v)$, and ultrapure water were used for coal sample digestion. Ultrapure water used during the experiment was prepared by a Milli-Q A10 system (Millipore, $18.2 \mathrm{M} \Omega \cdot \mathrm{cm}$ ). The guaranteed nitric acid and metal-oxide-semiconductor (MOS) reagent hydrofluoric acid were purified by a DuoPUR acid purification system (Milestone) which can reduce the impurities within the acids.

2.2.2. Gases. Ultrapure argon (99.999\%) was used as the cooling, auxiliary, and the nebulizer gas. High-purity oxygen used in the DMA-80 mercury analyzer acts both as a carrier gas and as a combustion-supporting gas.

2.2.3. Standard Solutions. Mercury standard solution $(1000 \mu \mathrm{g} / \mathrm{ml})$ was used to prepare five concentration levels ( 0 , $1,10,50$, and $100 \mu \mathrm{g} / \mathrm{L}$ ), which were used to establish calibration curves of mercury. Reagents for microwave digestion and ICP-MS analysis $\left(200 \mu \mathrm{g} / \mathrm{L}, 5 \% \mathrm{HNO}_{3}\right)$ were prepared using an auric standard solution $(1000 \mu \mathrm{g} / \mathrm{ml})$.

The $1000 \mu \mathrm{g} / \mathrm{ml}$ standard ${ }^{103} \mathrm{Rh}$ stock solution (GSB 041746-2004, National Center of Analysis and Testing for Nonferrous Metals and Electronic Materials) was used to prepare the internal standard $(10 \mu \mathrm{g} / \mathrm{L})$ for online addition during ICP-MS analytical process. The $100 \mu \mathrm{g} / \mathrm{ml}$ standard solution THM-TS-1 (Inorganic Ventures) containing elements lithium, cobalt, indium, and uranium was used to prepare the $1 \mu \mathrm{g} / \mathrm{L}$ tuning solution. All standard solutions were prepared in $2 \%(\mathrm{v} / \mathrm{v}) \mathrm{HNO}_{3}$ except for that the rinse solution was prepared in $5 \%(\mathrm{v} / \mathrm{v}) \mathrm{HNO}_{3}$.

2.2.4. Investigated Samples. In order to evaluate the suitability and accuracy of the ICP-MS and DMA- 80 mercury analyzer for coal mercury concentration determination, three NIST standard references of coal samples, i.e., SRM1632c, SRM2682b, and SRM2685b, were selected as references without further ashing.

2.3. Sample Digestion. Samples were digested by the closed TFM vessel UltraClave Microwave High-Pressure Reactor. Each NIST coal sample reference is crushed to $<200$ mesh $(<75 \mu \mathrm{m})$ prior to digestion. Four different digestion methods were used to find a way to completely digest the coal samples. Different reagent assemblages are as follows: (1) $50 \mathrm{mg}$ coal sample was added to $5 \mathrm{ml} \mathrm{HNO}_{3}$ and $2 \mathrm{ml} \mathrm{HF}$; (2) $50 \mathrm{mg}$ coal sample was added to $5 \mathrm{ml} \mathrm{HNO}_{3}, 2 \mathrm{ml} \mathrm{HF}$, and $2 \mathrm{ml} \mathrm{Au}$ standard solution $\left(200 \mu \mathrm{g} / \mathrm{L}, 5 \% \mathrm{HNO}_{3}\right)$; (3) $50 \mathrm{mg}$ coal sample was added to $5 \mathrm{ml} \mathrm{HNO}_{3}, 2 \mathrm{ml} \mathrm{HF}$, and $2 \mathrm{ml} \mathrm{Au}$ standard solution $\left(200 \mu \mathrm{g} / \mathrm{L}, 5 \% \mathrm{HNO}_{3}\right)$ was added after microwave digestion; (4) $100 \mathrm{mg}$ coal sample was added to $5 \mathrm{ml} \mathrm{HNO}_{3}, 1 \mathrm{ml} \mathrm{HF}$, and $2 \mathrm{ml} \mathrm{HCl}$. Since hydrofluoric acid was added during digestion, the HF-resistant PFAmade vessels were used during sample digestion and constant volume process.

Nitric acid and hydrofluoric acid are a common reagent combination used for the digestion of coal samples [56-59]. In the previous studies [57,60], $5 \mathrm{ml}$ of nitric acid and $2 \mathrm{ml}$ of hydrofluoric acid were used to completely digest the coal sample for trace elements concentration determination, and the test results were reliable. Mercury in coal occurs mainly in the following three forms: (1) mercury is related with sulfide (e.g., pyrite); (2) mercury is related with organic matter; (3) mercury is associated with silicate [13, 61-63]. The nitric acid was used to digest organic-associated and sulfide-associated mercury in coal, and the hydrofluoric acid was used to digest silicate-associated mercury in coal sample. In order to prohibit the volatility and adsorption of mercury, $2 \mathrm{ml}$ of gold solution was added to consolidate the mercury in the solution based on the original digestion scheme. In order to prevent mercury from being adsorbed on the wall of the volumetric flask during storage, $2 \mathrm{ml}$ of gold standard solution is added to the solution after microwave digestion. Based on previous studies, the presence of a small amount of hydrochloric acid can dissolve the cinnabar $(\mathrm{HgS})$ in the sample [64]. There are also some studies that use sulfuric acid and hydrogen peroxide in the digestion of samples $[55,65]$, but, because of the possibility of explosion, these reagents were not used in this study.

The basic load of the digestion tank in the UltraClave reactor consisted of $330 \mathrm{ml}$ ultrapure water, $30 \mathrm{ml} \mathrm{H}_{2} \mathrm{O}_{2}$ $(30 \%, \mathrm{v} / \mathrm{v})$, and $2 \mathrm{ml} \mathrm{H}_{2} \mathrm{SO}_{4}(98 \%, \mathrm{v} / \mathrm{v})$. The initial nitrogen pressure and the maximum temperature were set to 50-bars and $240^{\circ} \mathrm{C}$, respectively, for 75 minutes. The microwaveintroduced digestion procedure is shown in Table 1. To prevent mercury from volatilizing, the samples were transferred to the PFA volumetric flasks (resistant to HF corrosion) after the digestion was completed and cooled to room temperature. And then the digested samples were diluted with ultrapure water to $100 \mathrm{ml}$ for ICP-MS analysis.

\subsection{Instrumental Parameters}

2.4.1. ICP-MS. The short-term stability test was first performed in standard mode to optimize and test the position of torch and ion lens of the instrument. In order to get a maximum ion signal and stability, a $1 \mu \mathrm{g} / \mathrm{L}$ tuning solution, which was prepared from $10 \mu \mathrm{g} / \mathrm{ml}$ standard solution, was used to tune the facility. The parameters of the instrument after tuning are listed in Table 2. Since hydrofluoric acid causes certain damage to the vitreous sample-introduction system, the spray chamber and the rectangular tube made of hydrofluoric acid-resistant materials were used.

2.4.2. DMA-80 Mercury Analyzer. The critical feature of the Milestone DMA-80 mercury analyzer is that the samples regardless of solid, gaseous, or liquid can be directly measured without any pretreatment. Therefore, the loss of mercury during the sample preparation, mutual contamination, and environmental pollution are avoided, and reliable analytical data are ensured $[34,66]$. The entire analytical process of each sample takes only 5 minutes, supplemented by a 40 bit autosampler, and the Windowsbased operating software greatly improves the efficiency of the analysis. The parameters of the DMA- 80 mercury analyzer are listed in Table 3 . 
2.5. Rinse Solution. One problem with ICP-MS for mercury analysis is the memory effect of mercury during sample aspiration into the ICP-MS facility. In order to diminish the memory effect of mercury, various rinse solutions including ultrapure water, $2 \% \mathrm{HNO}_{3}, 2 \%$ ammonia solution, $5 \%$ $\mathrm{HNO}_{3}, 5 \%$ ammonia solution, and Au solution $(200 \mu \mathrm{g} / \mathrm{L}$, $5 \% \mathrm{HNO}_{3}$ ) were used to verify the removal mercury memory effect during the aspiration of the liquid sample introduced into the ICP-MS.

When the ICP-MS analyzes trace elements, $2 \% \mathrm{HNO}_{3}$ is a common rinse solution $[40,67]$. We adopted two different concentrations of the $\mathrm{HNO}_{3}$ solution, mainly to see the effect of concentration on the removal of memory effects. Different concentrations of ammonium hydroxide were also used to verify the elimination efficiency. The addition of gold solution to the rinse solution is common in the removal of mercury memory effects $[52,53,68]$. This is because $\mathrm{Au}^{2+}$ can form gold amalgam with mercury to effectively remove mercury adsorbed on the wall of the injection system $[39,49,69,70]$.

\section{Results and Discussion}

3.1. ICP-MS. The rinsing effects (Figure 1) by different rinse solutions showed that the $200 \mu \mathrm{g} / \mathrm{L} \mathrm{Au}{ }^{2+}-5 \% \mathrm{HNO}_{3}$ [49] rinse solution can effectively eliminate the mercury memory in the shortest time interval of $80 \mathrm{~s}$. By contrast, $2 \%$ and $5 \%$ $\mathrm{HNO}_{3}$ can reach the similar effects at longer time intervals, $320-340 \mathrm{~s}$ and $140 \mathrm{~s}$, respectively (Figure 1). As can be seen from Figure 1, the time intervals of 2\% and 5\% ammonium hydroxide reaching signal blank level are $500 \mathrm{~s}$ and 200-220 s, respectively. Therefore, the $200 \mu \mathrm{g} / \mathrm{L} \mathrm{Au}$ solution $+5 \% \mathrm{HNO}_{3}$ was used in this study.

Table 4 shows the determination coefficient of each method and the method detection limit (MDL) of mercury, which is calculated as three times the standard deviation of the average from the blank samples $(n=11)$. As can be seen from Table 4, the linearity of the calibration curve is satisfactory in the range from 0 to $100 \mu \mathrm{g} / \mathrm{L}$ with the determination coefficient $R^{2}$ higher than 0.9999 and the method detection limits low. The relative standard deviation (RSD) for each method is obtained by eleven repeated analyzes on NIST standard reference $1632^{\circ} \mathrm{C}$ (Table 4).

The observed concentrations of the reference materials determined by ICP-MS and the certified values are listed in Table 5, as well as the relative errors between the determined values and the certified values. It can be seen from the test results that the Mercury content of most samples is lower than the detection level, except for SRM2682b and SRM2685b in the second method. However, the measured values differ greatly from the certified values, and the relative errors are high. In order to verify the mercury content in the digested solutions, the digested solutions were measured by the DMA- 80 mercury analyzer. The test results obtained by the DMA-80 mercury analyzer are listed in Table 5. From the
TABLE 1: Microwave program for sample digestion.

\begin{tabular}{lcccc}
\hline Step & Time (minute) & $\mathrm{T}\left({ }^{\circ} \mathrm{C}\right)$ & $\mathrm{P}$ (bar) & $\mathrm{Mp}$ (watt) \\
\hline 1 & 12 & 60 & 100 & 1000 \\
2 & 20 & 125 & 100 & 1000 \\
3 & 8 & 160 & 130 & 1000 \\
4 & 15 & 240 & 160 & 1200 \\
5 & 60 & 240 & 160 & 1000 \\
Cooling time & 60 & & & \\
\hline
\end{tabular}

$T$, temperature; $\mathrm{P}$, pressure; MP, microwave power

test results of the DMA- 80 mercury analyzer, it can be seen that the content of mercury in the digested sample is lower than the detection level of DMA-80 mercury analyzer or the measured mercury content is close to the blank level.

In this study, ${ }^{202} \mathrm{Hg}$ was selected as analytical isotope due to its relatively high content and high sensitivity [71-73]. In the process of analyzing mercury content with ICP-MS, ${ }^{103} \mathrm{Rh}(10 \mu \mathrm{g} / \mathrm{L})$ was selected as the internal standard due to its extremely low concentration in coal [57] and its excellent application in the testing of trace elements in coal $[57,60]$.

During the experiment, $10 \mathrm{ppb}$ and $50 \mathrm{ppb}$ of $\mathrm{Hg}$ standard solutions were tested as samples to verify the stability of instrument during the test. The test value of $10 \mathrm{ppb}$ of $\mathrm{Hg}$ standard solution was $9.659(\mathrm{RE}=3.41 \%)$, and the test value of $50 \mathrm{ppb}$ of $\mathrm{Hg}$ standard solution was $51.7(\mathrm{RE}=3.40 \%)$ and $47.65(\mathrm{RE}=4.70 \%)$. From the test results of the $\mathrm{Hg}$ standard solutions, it can be concluded that ICP-MS can accurately test the mercury content in solutions. The rate of internal standard solution recovery of test samples $(95.97 \%-$ $108.14 \%)$ indicates that the ${ }^{103} \mathrm{Rh}(10 \mu \mathrm{g} / \mathrm{L})$ solution is suitable for use as an internal standard solution.

There are a number of reasons that account for the inaccuracy of the test results: (1) mercury in coal volatilizes during the storage stage [74]; (2) even if the concentration of mercury in coal is very low, it is also easy to adsorb on the wall of container or the surrounding atmosphere [39]; (3) the wall of the containers and the injection system of instrument can be easily penetrated by some mercury species $[39,75]$; (4) mercury was adsorbed by colloids or particles in solution [22]; (5) mercury is unstable in polyethylene containers and is easily lost [22, 74-76]. Comparing the test results of ICP-MS and DMA-80 mercury analyzer for the digested solution, the inaccuracy of the test results may be due to volatilization of mercury during the digestion procedure.

3.2. DMA-80 Mercury Analyzer. Table 6 shows the results of the samples tested by the DMA- 80 mercury analyzer. From the test results, it can be seen that the highest relative error is $15.92 \%$. The relative error of SRM $1632^{\circ} \mathrm{C}$ is below $1 \%$, and the relative error of SRM 2685b is $5.70 \%$. The DMA- 80 mercury analyzer is reliable for the test results for all three samples. 
TABLE 2: ICP-MS working conditions.

\begin{tabular}{lccc}
\hline Item & Value/status & Item & Value/status \\
\hline Plasma RF power & $1400 \mathrm{~W}$ & Uptake time & $60 \mathrm{~s}$ \\
Nebulizer gas flow & $1.01 \mathrm{~L} / \mathrm{min}$ & Washout time & $100 \mathrm{~s}$ \\
Auxiliary gas flow & $0.90 \mathrm{~L} / \mathrm{min}$ & Pole bias & $-6.0 \mathrm{~V}$ \\
Cool gas flow & $14 \mathrm{~L} / \mathrm{min}$ & Hexapole bias & $-5.0 \mathrm{~V}$ \\
Sampling depth & $100 \mathrm{steps}$ & Number of main runs & 3 \\
ICP-MS interface & Nickel xt & Dwell time & $10 \mathrm{~ms}$ \\
Peristaltic pump speed & $30 \mathrm{rpm}$ & Acquisition mode & Peak jumping mode \\
Spray chamber temperature & $2^{\circ} \mathrm{C}$ & Number of channels & 3 \\
\hline
\end{tabular}

TABLE 3: Instrumental parameters of the DMA- 80 mercury analyzer.

\begin{tabular}{lccc}
\hline Item & Value (status) & Item & Value (status) \\
\hline Injection volume & $0.1 \mathrm{~g}$ & Carrier gas & Oxygen, 200 ml (min) \\
Wavelength & $253.65 \mathrm{~nm}$ & Measuring range & $0.0002 \mathrm{ng}-30000 \mathrm{ng}$ \\
Repeatability & $\mathrm{RSD}<1.5 \%$ & Power supply & $220 \mathrm{~V}, 50 \mathrm{~Hz}$ \\
Detector & Silicon-UV photodetector & Detection limit & $0.005 \mathrm{ng}$ \\
\hline
\end{tabular}

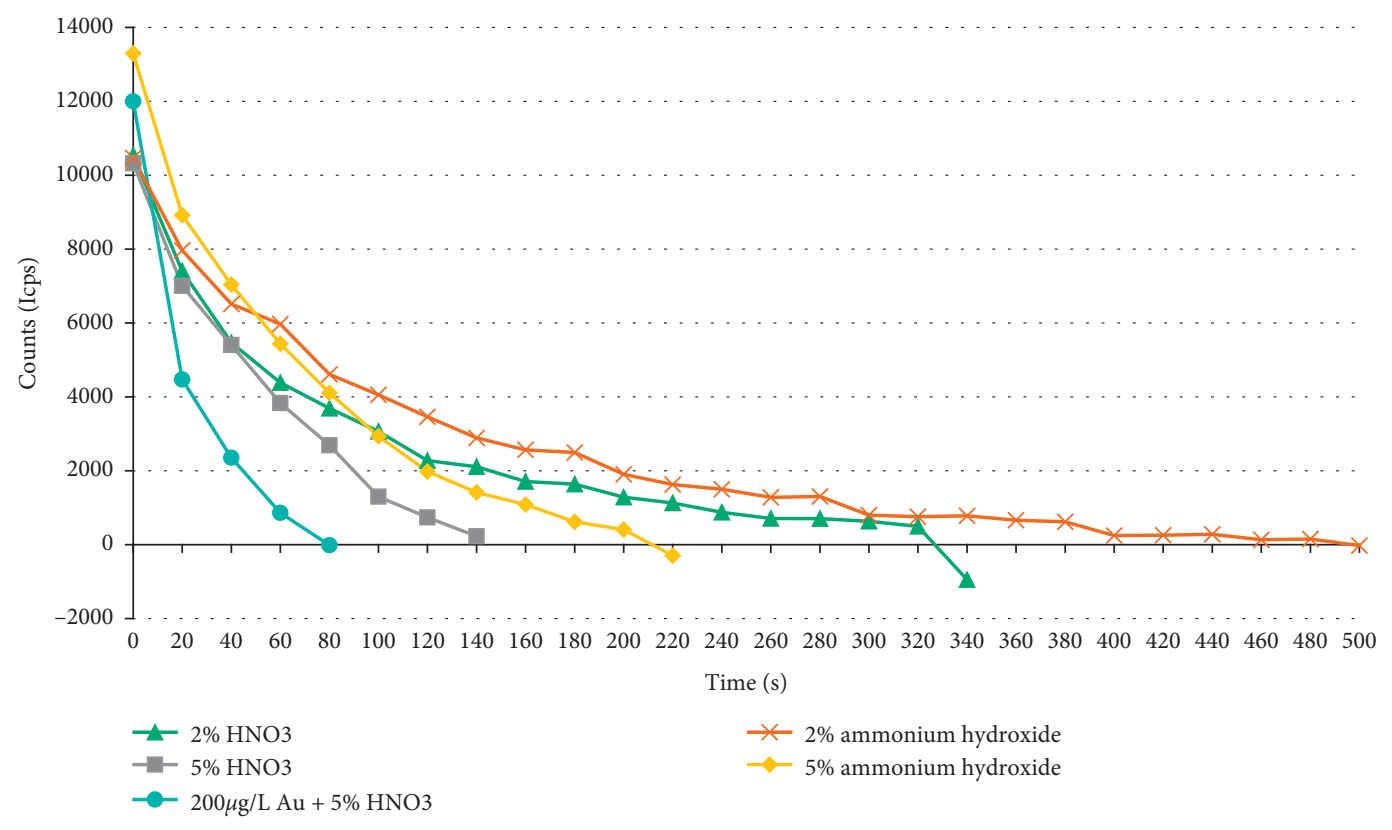

FIGURE 1: Removal effects of mercury memory by different rinse solutions.

TABLE 4: Calibration curves and method detection limit (MDL) of Hg.

\begin{tabular}{|c|c|c|c|c|}
\hline Methods & Linearity (ug/L) & Determination coefficient & MDL (ug/L) & RSD (\%) \\
\hline $50 \mathrm{mg}$ sample $(\mathrm{HNO} 3+\mathrm{HF})$ & $0-100$ & 0.999969 & 1.220 & 0.34 \\
\hline $50 \mathrm{mg}$ sample $(\mathrm{HNO} 3+\mathrm{HF}+\mathrm{Au})$ & $0-100$ & 0.999926 & 1.107 & 0.29 \\
\hline $50 \mathrm{mg}$ sample $(\mathrm{HNO} 3+\mathrm{HF}+\mathrm{Au}($ after $))$ & $0-100$ & 0.999929 & 0.310 & 0.94 \\
\hline $100 \mathrm{mg}$ sample $(\mathrm{HNO} 3+\mathrm{HF}+\mathrm{HCl})$ & $0-100$ & 0.999929 & 1.000 & 0.10 \\
\hline
\end{tabular}


TABLE 5: Observed and certified values of mercury $(\mu \mathrm{g} / \mathrm{kg})$ in the NIST coal references, as well as internal standard solution recovery (Rec, \%) and relative errors (RE, \%) of the ICP-MS analysis, and the observed (Obs) values of $\mathrm{Hg}(\mu \mathrm{g} / \mathrm{kg})$ in the digested solutions measured by the DMA-80 mercury analyzer.

\begin{tabular}{|c|c|c|c|c|c|c|}
\hline \multirow{2}{*}{ Methods } & \multirow{2}{*}{ Samples } & \multicolumn{4}{|c|}{ ICP-MS } & \multirow{2}{*}{$\begin{array}{c}\text { DMA-80 } \\
\text { Obs }\end{array}$} \\
\hline & & $\operatorname{Rec}(\%)$ & Certified & Observed & ${ }^{\mathrm{a}} \mathrm{RE}$ & \\
\hline \multirow{3}{*}{$50 \mathrm{mg}$ sample $\left(\mathrm{HNO}_{3}+\mathrm{HF}\right)$} & SRM1632c & 106.28 & $93.8+3.7$ & bdbll & 1 & bdbdl \\
\hline & SRM2682b & 99.99 & $108.8+2.9$ & bdl & l & b bdl \\
\hline & SRM2685b & 95.97 & $146.2+10.6$ & b bdl & I & b bdl \\
\hline \multirow{3}{*}{$50 \mathrm{mg}$ sample $\left(\mathrm{HNO}_{3}+\mathrm{HF}+\mathrm{au}\right)$} & SRM1632c & 101.48 & $93.8+3.7$ & bbdl & 1 & bbdl \\
\hline & SRM2682b & 104.66 & $108.8+2.9$ & 1651.79 & 1418.19 & b bdl \\
\hline & SRM2685b & 104.88 & $146.2+10.6$ & 720.68 & 79.71 & b bdl \\
\hline \multirow{3}{*}{$50 \mathrm{mg}$ sample $\left(\mathrm{HNO}_{3}+\mathrm{HF}+\mathrm{Au}(\right.$ after $\left.)\right)$} & SRM1632c & 99.19 & $93.8+3.7$ & bdbdl & 1 & b bdl \\
\hline & SRM2682b & 100.36 & $108.8+2.9$ & bdl & l & 0.0064 \\
\hline & SRM2685b & 104.51 & $146.2+10.6$ & b bdl & 1 & 0.0089 \\
\hline \multirow{3}{*}{$100 \mathrm{mg}$ sample $\left(\mathrm{HNO}_{3}+\mathrm{HF}+\mathrm{HCl}\right)$} & SRM1632c & 103.26 & $93.8+3.7$ & b bdl & 1 & 0.0082 \\
\hline & SRM2682b & 107.61 & $108.8+2.9$ & b bdl & I & 0.0192 \\
\hline & SRM $2685 b$ & 108.14 & $146.2+10.6$ & b bdl & I & 0.0192 \\
\hline
\end{tabular}

${ }^{\mathrm{a}} \mathrm{RE}=(\mid \text { observed-certified } \mid / \text { certified })^{*} 100[60] .{ }^{\mathrm{b}} \mathrm{bdl}=$ below detection level.

TABle 6: Certified (Cer) and observed (Obs) value of mercury in NIST standard reference coal samples.

\begin{tabular}{lccc}
\hline DMA-80 mercury analyzer & SRM1632c & SRM2682b & SRM2685b \\
\hline Cer $(\mu \mathrm{g} / \mathrm{kg})$ & $93.8+3.7$ & $108.8+2.9$ & $146.2+10.6$ \\
Obs $(\mu \mathrm{g} / \mathrm{kg})$ & 93.36 & 91.48 & 137.87 \\
${ }^{\mathrm{a}} \mathrm{RE}(\%)$ & 0.47 & 15.92 & 5.70 \\
\hline
\end{tabular}

${ }^{\mathrm{a}} \mathrm{RE}=(\mid$ observed-certified $\mid /$ certified $){ }^{*} 100[60]$.

\section{Conclusions}

Although ICP-MS has been used for concentration determination of mercury in coal and could accurately determine mercury in solutions, we do not recommend the use of this technique. Instead, a direct mercury analyzer is the most reliable approach. The major reason for this is mercury's high volatility during sample pretreatment process, even if the digestion is conducted in a closed-vessel digestion system. On the other hand, an optimized rinse solution ( $\mathrm{Au}$ solution, $200 \mu \mathrm{g} / \mathrm{L}, 5 \% \mathrm{HNO}_{3}$ ) is recommended to diminish mercury memory in the ICP-MS spray chamber to a blank level within 80 seconds.

\section{Data Availability}

The data used to support the findings of this study are included within the article.

\section{Conflicts of Interest}

The authors declare that there are no conflicts of interest regarding the publication of this paper.

\section{Acknowledgments}

This work was supported by the National Natural Science Foundation of China (nos. 41420104001 and U1810202), the "111" Project (no. B17042), and the program for Changjiang
Scholars and Innovative Research Team in University (IRT_17R104).

\section{References}

[1] G. UNEP, "Mercury Assessment 2013 Sources, Emissions, Releases and Environmental Transport," 2013, https://www. unenvironment.org/zh-hans/node/1241.

[2] J. Entwisle, "The determination of mercury in microwave digests of foodstuffs by ICP-MS," Am Care Lab, vol. 36, no. 6, pp. 11-14, 2004.

[3] E. G. Pacyna, J. M. Pacyna, K. Sundseth et al., "Global emission of mercury to the atmosphere from anthropogenic sources in 2005 and projections to 2020," Atmospheric Environment, vol. 44, no. 20, pp. 2487-2499, 2010.

[4] USEPA, "Basic Information about Mercury," 2017, https:// www.epa.gov/mercury/basic-information-about-mercury.

[5] S. E. Long and W. R. Kelly, "Determination of mercury in coal by isotope dilution cold-vapor generation inductively coupled plasma mass spectrometry," Analytical Chemistry, vol. 74, no. 7, pp. 1477-1483, 2002.

[6] M. Wang, Y. Zhang, W.-Y. Feng et al., "Determination of mercury in fish by isotope dilution inductively coupled plasma-mass spectrometry," Chinese Journal of Analytical Chemistry, vol. 35, no. 7, pp. 945-948, 2007.

[7] National Research Council, Toxicological Effects of Methylmercury, National Academy Press, Washington, DC, 2010.

[8] M. P. Ketris and Y. E. Yudovich, "Estimations of Clarkes for Carbonaceous biolithes: world averages for trace element contents in black shales and coals," International Journal of Coal Geology, vol. 78, no. 2, pp. 135-148, 2009.

[9] R. B. Finkelman, "Trace and minor elements in coal," in Organic Geochemistry, M. H. Engel and S. Macko, Eds., pp. 593-607, Plenum, NY, New York, 1993.

[10] S. Dai, D. Ren, C.-L. Chou, R. B. Finkelman, V. V. Seredin, and Y. Zhou, "Geochemistry of trace elements in Chinese coals: a review of abundances, genetic types, impacts on human health, and industrial utilization," International Journal of Coal Geology, vol. 94, pp. 3-21, 2012.

[11] R. B. Finkelman, "Modes of Occurrence of Trace Elements in Coal," PhD Thesis, p. 302, University of Maryland, College Park, Maryland, 1980. 
[12] Y. Zhou, "Mercury distribution types and existence form in anthracite of Laochang mining area," Coal Geology \& Exploration, vol. 22, no. 3, pp. 17-21, 1994.

[13] Y. E. Yudovich and M. P. Ketris, "Mercury in coal: a review," International Journal of Coal Geology, vol. 62, no. 3, pp. 107-134, 2005.

[14] 2018 https:/www.bp.com/content/dam/bp/en/corporate/pdf/ energy-economics/statistical-review/bp-stats-review-2018-fullreport.pdf BP Statistical Review of World Energy June 2018.

[15] N. Pirrone, S. Cinnirella, X. Feng et al., "Global mercury emissions to the atmosphere from natural and anthropogenic sources," in Mercury Fate and Transport in the Global Atmosphere, pp. 1-47, Springer, Berlin, Germany, 2009.

[16] 2018 http://www.stats.gov.cn/tjsj/ndsj/ China Statistical Yearbook 2018.

[17] M. B. A. Vasconcellos, P. Bode, G. Paletti et al., "Determination of mercury and selenium in hair samples of Brazilian Indian populations living in the Amazonic region by NAA," Journal of Radioanalytical and Nuclear Chemistry, vol. 244, no. 1, pp. 81-85, 2000.

[18] E. Orvini, T. E. Gills, and P. D. LaFleur, "Method for determination of selenium, arsenic, zinc, cadmium, and mercury in environmental matrices by neutron activation analysis," Analytical Chemistry, vol. 46, no. 9, pp. 1294-1297, 1974.

[19] W. Y. Feng, C. F. Chai, and Q. F. Qian, "A new neutron activation technique for simultaneous determination of inorganic and total mercury contents in human hair," Journal of Radioanalytical and Nuclear Chemistry Letters, vol. 212, no. 1, pp. 61-68, 1996.

[20] C. Y. Zhou, M. K. Wong, L. L. Koh, and Y. C. Wee, "Comparison of acid mixtures in high-pressure microwave digestion methods for the determination of the total mercury in sediments by cold-vapor atomic absorption spectrometry," Analytical Sciences, vol. 12, no. 3, pp. 471-476, 1996.

[21] W. L. Clevenger, B. W. Smith, and J. D. Winefordner, "Trace determination of mercury: a review," Critical Reviews in Analytical Chemistry, vol. 27, no. 1, pp. 1-26, 1997.

[22] H. Morita, H. Tanaka, and S. Shimomura, "Atomic fluorescence spectrometry of mercury: principles and developments," Spectrochimica Acta Part B: Atomic Spectroscopy, vol. 50, no. 1, pp. 69-84, 1995.

[23] M. Rose, M. Knaggs, L. Owen, and M. Baxter, "A review of analytical methods for lead, cadmium, mercury, arsenic and tin determination used in proficiency testing," Journal of Analytical Atomic Spectrometry, vol. 16, no. 9, pp. 1101-1106, 2001.

[24] W. Geng, T. Nakajima, H. Takanashi, and A. Ohki, "Determination of mercury in ash and soil samples by oxygen flask combustion method-cold vapor atomic fluorescence spectrometry (CVAFS)," Journal of Hazardous Materials, vol. 154, no. 1-3, pp. 325-330, 2008.

[25] A. W. Rea and G. J. Keeler, "Microwave digestion and analysis of foliage for total mercury by cold vapor atomic fluorescence spectroscopy," Biogeochemistry, vol. 40, no. 2/3, pp. 115-123, 1998.

[26] N. Bloom and W. F. Fitzgerald, "Determination of volatile mercury species at the picogram level by low-temperature gas chromatography with cold-vapour atomic fluorescence detection," Analytica Chimica Acta, vol. 208, pp. 151-161, 1988.

[27] M. J. Da Silva, A. P. S. Paim, M. F. Pimentel, M. L. Cervera, and M. De la Guardia, "Determination of mercury in rice by cold vapor atomic fluorescence spectrometry after microwave-assisted digestion," Analytica Chimica Acta, vol. 667, no. 1-2, pp. 43-48, 2010.

[28] M. Horvat, V. Lupšina, and B. Pihlar, "Determination of total mercury in coal fly ash by gold amalgamation cold vapour atomic absorption spectrometry," Analytica Chimica Acta, vol. 243, pp. 71-79, 1991.

[29] M. J. Campbell, G. Vermeir, R. Dams, and P. Quevauviller, "Influence of chemical species on the determination of mercury in a biological matrix (cod muscle) using inductively coupled plasma mass spectrometry," Journal of Analytical Atomic Spectrometry, vol. 7, no. 4, pp. 617-621, 1992.

[30] A. Morales-Rubio, M. Mena, and C. W. McLeod, "Rapid determination of mercury in environmental materials using on-line microwave digestion and atomic fluorescence spectrometry," Analytica Chimica Acta, vol. 308, no. 1-3, pp. 364-370, 1995.

[31] W. B. Zhang, Z. F. Su, X. F. Chu, and X. A. Yang, "Evaluation of a new electrolytic cold vapor generation system for mercury determination by AFS," Talanta2010, vol. 80, no. 5, pp. 2106-2112.

[32] H. Zhang, J. W. Gao, X. Y. Wang, N. N. Di, and J. Kang, "Rapid determination of trace mercury in coal by direct mercury analyzer," Coal Quality Technology, no. 1, pp. 17-20, 2014.

[33] C. Maggi, M. T. Berducci, J. Bianchi, M. Giani, and L. Campanella, "Methylmercury determination in marine sediment and organisms by Direct Mercury Analyser," Anal. Chim. Acta, vol. 641, no. 1-2, pp. 32-36, 2009.

[34] S. Haynes, R. D. Gragg, E. Johnson, L. Robinson, and C. E. Orazio, "An evaluation of a reagentless method for the determination of total mercury in aquatic life," Water, Air, \& Soil Pollution, vol. 172, no. 1-4, pp. 359-374, 2006.

[35] J. V. Cizdziel, C. Tolbert, and G. Brown, "Direct analysis of environmental and biological samples for total mercury with comparison of sequential atomic absorption and fluorescence measurements from a single combustion event," Spectrochimica Acta Part B: Atomic Spectroscopy, vol. 65, no. 2, pp. 176-180, 2010.

[36] R. Dumarey, P. Verbiest, and R. Dama, "Optimization of a wet digestion method for the determination of mercury in coal samples by cold vapor atomic absorption spectrometry (CVAAS)," Bull. Soc. Chim. Belg.vol. 94, no. 5, pp. 351-357, 1985.

[37] T. H. Nguyen, J. Boman, M. Leermakers, and W. Baeyens, "Mercury determination in environmental samples using EDXRF and CV-AAS," X-Ray Spectrometry, vol. 27, no. 4, pp. 277-282, 1998.

[38] USEPA: https://www.epa.gov/homeland-security-research/epamethod-7473-sw-846-mercury-solids-and-solutions-thermal-dec omposition EPA Method 7473 (SW-846): Mercury in Solids and Solutions by Thermal Decomposition, Amalgamation, and Atomic Absorption Spectrophotometry.

[39] M. A. López-Antón, M. Díaz-Somoano, R. Ochoa-González, and M. R. Martínez-Tarazona, "Analytical methods for mercury analysis in coal and coal combustion by-products," International Journal of Coal Geology, vol. 94, pp. 44-53, 2012.

[40] Y. Li, C. Chen, B. Li et al., "Elimination efficiency of different reagents for the memory effect of mercury using ICP-MS," Journal of Analytical Atomic Spectrometry, vol. 21, no. 1, pp. 94-96, 2006.

[41] L. Jian, W. Goessler, and K. J. Irgolic, "Mercury determination with ICP-MS: signal suppression by acids," Fresenius' Journal of Analytical Chemistry, vol. 366, no. 1, pp. 48-53, 2000. 
[42] R. Falciani, E. Novaro, M. Marchesini, and M. Gucciardi, "Multi-element analysis of soil and sediment by ICP-MS after a microwave assisted digestion method," Journal of Analytical Atomic Spectrometry, vol. 15, no. 5, pp. 561-565, 2000.

[43] B. Passariello, M. Barbaro, S. Quaresima, A. Casciello, and A. Marabini, "Determination of mercury by inductively coupled plasma-mass spectrometry," Microchemical Journal, vol. 54, no. 4, pp. 348-354, 1996.

[44] J.-y. Zhang, W. Guo, and W. Guo, "Elimination of memory effects and simultaneous determination of $\mathrm{B}, \mathrm{Br}, \mathrm{I}, \mathrm{Hg}, \mathrm{Bi}$, and $\mathrm{Sb}$ in groundwater samples by inductively coupled plasma mass spectrometry," Atomic Spectroscopy, vol. 35, no. 3, pp. 97-102, 2014.

[45] S. M. Maia, D. Pozebon, and A. J. Curtius, "Determination of $\mathrm{Cd}, \mathrm{Hg}, \mathrm{Pb}$ and $\mathrm{Tl}$ in coal and coal fly ash slurries using electrothermal vaporization inductively coupled plasma mass spectrometry and isotopic dilution," Journal of Analytical Atomic Spectrometry, vol. 18, no. 4, pp. 330-337, 2003.

[46] B. F. Shi, D. Liu, X. M. Zhang, and X. L. Yu, Determination of Mercury,Beryllium, Arsenic, and Uranium in Coal Samples by Inductively Coupled Plasma-Mass Spectrometry with Microwave Digestion, Research \& Exploration in Laboratory, Guangzhou, China, 2016.

[47] F. G. Antes, F. A. Duarte, M. F. Mesko et al., "Determination of toxic elements in coal by ICP-MS after digestion using microwave-induced combustion," Talanta, vol. 83, no. 2, pp. 364-369, 2011.

[48] C. F. Harrington, S. A. Merson, and T. M. D’ Silva, "Method to reduce the memory effect of mercury in the analysis of fish tissue using inductively coupled plasma mass spectrometry," Analytica Chimica Acta, vol. 505, no. 2, pp. 247-254, 2004.

[49] J. Allibone, E. Fatemian, and P. J. Walker, "Determination of mercury in potable water by ICP-MS using gold as a stabilising agent," Journal of Analytical Atomic Spectrometry, vol. 14, no. 2, pp. 235-239, 1999.

[50] X. X. Zhao, Z. S. Zhao, and L. L. Wang, "Determining mercury in water by ICP-MS," China Measurement \& TEST, vol. 39, no. 6, pp. 50-52, 2013.

[51] A. Woller, H. Garraud, F. Martin, O. F. X. Donard, and P. Fodor, "Determination of total mercury in sediments by microwave-assistedDigestion-flow injection-inductively coupled plasma MassSpectrometry," Journal of Analytical Atomic Spectrometry, vol. 12, no. 1, pp. 53-56, 1997.

[52] J. A. Moreton and H. T. Delves, "Simple direct method for the determination of total mercury levels in blood and urine and nitric acid digests of fish by inductively coupled plasma mass spectrometry," Journal of Analytical Atomic Spectrometry, vol. 13, no. 7, pp. 659-665, 1998.

[53] J. Yoshinaga and M. Morita, "Determination of mercury in biological and environmental samples by inductively coupled plasma mass spectrometry with the isotope dilution technique," Journal of Analytical Atomic Spectrometry, vol. 12, no. 4, pp. 417-420, 1997.

[54] W. Chen, P. Wee, and I. D. Brindle, "Elimination of the memory effects of gold, mercury and silver in inductively coupled plasma atomic emission spectroscopy," Journal of Analytical Atomic Spectrometry, vol. 15, no. 4, pp. 409-413, 2000.

[55] N. Mketo, P. N. Nomngongo, and J. C. Ngila, "An innovative microwave-assisted digestion method with diluted hydrogen peroxide for rapid extraction of trace elements in coal samples followed by inductively coupled plasma-mass spectrometry," Microchemical Journal, vol. 124, pp. 201-208, 2016.
[56] G. Xin, X. Jia, and C. Zheng, "A comparison of microwave and conventional wet acid digestion method for the determination of mercury in coal and coal ash," Energy Sources, Part A: Recovery, Utilization, and Environmental Effects, vol. 34, no. 16, pp. 1516-1522, 2012.

[57] X. Li, S. Dai, W. Zhang, T. Li, X. Zheng, and W. Chen, "Determination of as and Se in coal and coal combustion products using closed vessel microwave digestion and collision/reaction cell technology (CCT) of inductively coupled plasma mass spectrometry (ICP-MS)," International Journal of Coal Geology, vol. 124, no. 3, pp. 1-4, 2014.

[58] Y. Xu, A. Iwashita, T. Nakajima, H. Yamashita, H. Takanashi, and A. Ohki, "Effect of HF addition on the microwaveassisted acid-digestion for the determination of metals in coal by inductively coupled plasma-atomic emission spectrometry," Talanta, vol. 66, no. 1, pp. 58-64, 2005.

[59] F. Low and L. Zhang, "Microwave digestion for the quantification of inorganic elements in coal and coal ash using ICPOES," Talanta, vol. 101, pp. 346-352, 2012.

[60] S. Dai, W. Song, L. Zhao et al., "Determination of boron in coal using closed-vessel microwave digestion and inductively coupled plasma mass spectrometry (ICP-ms)," Energy \& Fuels, vol. 28, no. 7, pp. 4517-4522, 2014.

[61] L. Zheng, G. Liu, and C. L. Chou, "The distribution, occurrence and environmental effect of mercury in Chinese coals," Science of the Total Environment, vol. 384, no. 1-3, pp. 374383, 2007.

[62] X. Feng and Y. Hong, "Modes of occurrence of mercury in coals from Guizhou, People's Republic of China," Fuel, vol. 78, no. 10, pp. 1181-1188, 1999.

[63] G. Luo, H. Yao, M. Xu, R. Gupta, and Z. Xu, "Identifying modes of occurrence of mercury in coal by temperature programmed pyrolysis," Proceedings of the Combustion Institute, vol. 33, no. 2, pp. 2763-2769, 2011.

[64] H. Agemian and A. S. Y. Chau, "An improved digestion method for the extraction of mercury from environmental samples," The Analyst, vol. 101, no. 1199, pp. 91-95, 1976.

[65] Y. G. Luo, J. H. Shi, and J. H. Sun, "Discussion on determination of mercury in coal using microwave digestion,hydride generation cold atomic absorption spectrometry," Coal Quality Technology, 2016.

[66] N. K. Roy and S. S. Bose, "Determination of mercury in thirty-three international stream sediment and soil reference samples by direct mercury analyser," Geostandards and Geoanalytical Research, vol. 32, no. 3, pp. 331-335, 2008.

[67] C. Almeida, M. Vasconcelos, M. Barbaste, and B. Medina, "ICPMS multi-element analysis of wine samples - a comparative study of the methodologies used in two laboratories," Analytical and Bioanalytical Chemistry, vol. 374, no. 2, pp. 314-322, 2002.

[68] M. Mahar, J. F. Tyson, K. Neubauer, and Z. Grosser, "High throughput sample introduction system for the analysis of drinking waters and wastewaters by ICP-MS," Journal of Analytical Atomic Spectrometry, vol. 23, no. 9, pp. 1204-1213, 2008.

[69] Y. Yuan, Y. Zhou, and T. Wang, "Determination of mercury by ICP-MS with L-cysteine and gold," Chinese Journal of Health Laboratory Technology, vol. 26, 2016.

[70] J. Zhang, "Eliminating the memory effect of determining mercury by ICP-ms," Journal of Jiyuan Vocational \& Technical College, vol. 14, 2015.

[71] Z. Y. Gan, N. N. Shen, Y. R. Li, L. Xu, and Z. Xu, "Research on determination of total mercury in water by ICP-ms," Environmental Science \& Technology, vol. 30, 2017. 
[72] D. S. Bushee, "Speciation of mercury using liquid chromatography with detection by inductively coupled plasma mass spectrometry," The Analyst, vol. 113, no. 8, pp. 1167-1170, 1988.

[73] M. J. Powell, E. S. K. Quan, D. W. Boomer, and D. R. Wiederin, "Inductively coupled plasma mass spectrometry with direct injection nebulization for mercury analysis of drinking water," Analytical Chemistry, vol. 64, no. 19, pp. 2253-2257, 1992.

[74] J. M. Lo and C. M. Wai, "Mercury loss from water during storage. Mechanisms and prevention," Analytical Chemistry, vol. 47, no. 11, pp. 1869-1870, 1975.

[75] M. H. Bothner and D. E. Robertson, "Mercury contamination of sea water samples stored in polyethylene containers," Analytical Chemistry, vol. 47, no. 3, pp. 592-595, 1975.

[76] C. Feldman, "Preservation of dilute mercury solutions," Analytical Chemistry, vol. 46, no. 1, pp. 99-102, 1971. 